\title{
Concepções do processo ensino-aprendizagem: um estudo com professores de Medicina
}

\section{Conceptions of the teaching-learning process: a study of medical professors}

\author{
Angela Maria Moreira Canuto ${ }^{\mathrm{I}}$ \\ Sylvia Helena Souza da Silva Batista ${ }^{\mathrm{II}}$
}

\section{PALAVRAS-CHAVE \\ - Educação médica \\ - Docentes de medicina \\ - Educação de Graduação em Medicina}

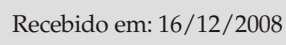

- Education, Medi
Undergraduate

- Medical. Education

- Faculty, Medical

\begin{abstract}
R E S U M O
Este artigo aborda a docência médica como um processo de construção social, que articula condicionantes político-acadêmicos, pedagógicos, pessoais e intersubjetivos. Com o objetivo de analisar as concepções de professores-médicos que ingressaram nas últimas cinco décadas na Universidade Federal de Alagoas sobre o ensino, a aprendizagem e os processos de formação docente em Medicina, delineou-se uma pesquisa com 21 docentes que atuam ou atuaram no curso de Medicina daquela universidade nas décadas de 1950 a 1990. Na coleta de dados foram utilizadas entrevistas semiestruturadas, tratadas a partir da análise de conteúdo, do tipo temática. No âmbito do ensinar e do aprender em Medicina, os professores entrevistados destacaram a dimensão relacional entre professor e aluno. As trajetórias de formação mostraram-se influenciadas pelo autodidatismo, e a falta de sistematização de uma formação didático-pedagógica foi indicada pelos professores como uma lacuna em seus itinerários na docência médica. A formação docente em Medicina apresentou-se como um processo que abrange múltiplas experiências e modelos, evidenciando que se tornar professor de medicina é complexo, plural e multifacetado.
\end{abstract}

\section{A B S T R A C T}

This article addresses medical teaching as a social construction process, linking academic policy, pedagogical, personal, and inter-subjective factors. With the aim of analyzing the conceptions towards teaching practice, learning, and faculty training in medicine among medical professors at the Federal University in Alagoas, Brazil, a study was designed with a sample of 21 professors that joined the university's medical faculty from the 1950s to the 1990s. Data collection used semi-structured interviews, submitted to thematic content analysis. Within the context of teaching and learning in medicine, the professors highlighted the faculty-student relationship. Analysis of faculty background showed that many professors were self-taught, and there was an evident lack of systematization, which the interviewees indicated as a gap in their medical teaching careers. Faculty training in medicine appeared as a process encompassing multiple experiences and models, highlighting that to become a medical professor is a complex, plural, and multifaceted process. 


\section{INTRODUÇÃO}

A docência tem sido objeto de análises e estudos no movimento de transformação do ensino superior em saúde no Brasil. Diferentes inovações educacionais, incluindo integração disciplinar, aprendizagem baseada em problemas, currículo centrado na comunidade e currículo nuclear, têm sido implantadas e avaliadas. Elas traduzem, produzem e são geradas por concepções diversas, e devem ser submetidas à reflexão crítico-teórica ${ }^{1}$.

Os estudos de Pimenta e Anastasiou ${ }^{2}$ descrevem com clareza um traço que tem marcado a docência universitária: a secundarização do estatuto de profissão acaba carreando uma visão baseada na improvisação e na desqualificação da formação didático-pedagógica para atuar no ensino superior.

Pesquisadores como Rodrigues e Esteves ${ }^{3}$, Pimentel ${ }^{4}$ e Perdigão ${ }^{5}$ destacaram em seus estudos que o professor universitário demanda reconhecer-se como formador e se comprometer com a aprendizagem dos alunos, assumindo uma postura científica que alie preocupação com valores, crenças, saberes experienciais e atitudes de cidadania.

Entende-se que as transformações sociais comportam um diálogo com as propostas pedagógicas, sendo necessário que o professor assuma um lugar de mediador no processo de formação do profissional de Saúde, estruturando cenários de aprendizagem que sejam significativos e problematizadores da prática profissional ${ }^{6,7}$.

Não se pode dar pouco valor à complexidade que envolve a docência em Saúde. É preciso reconhecer a existência de uma triangulação central entre ensino, aprendizagem e assistência no contexto das especificidades que caracterizam os cenários do processo ensino-aprendizagem e seus atores - professor, aluno, pacientes, profissionais de saúde e comunidade-, cada qual com demandas específicas ${ }^{8}$.

Nesse cenário, o lugar do professor emerge com significativa relevância, respondendo por algumas ênfases e modelos que irão marcar os modos de atuação na prática de atenção à saúde. A conciliação de uma prática especializada em dada área profissional da saúde com a proposta de formação generalista na graduação tem constituído uma árdua tarefa para superar a dicotomia generalista-especialista.

Na maioria das vezes, o docente da área da saúde é contratado tendo-se como critério apenas a qualidade do seu desempenho como profissional e/ou pesquisador ${ }^{6}$. Fica implícito que a competência profissional e/ou acadêmica assegura a competência didática. Ao contrário de algumas outras áreas, não se exige formação sistematizada que instrumentalize a sua maneira de conceber e desenvolver o processo ensino-aprendizagem.

\section{Ribeiro $^{9}$ afirma ser necessário}

recuperar uma sabedoria docente que não está circunscrita pelo discurso normativo da didática, mas pelo reconhecimento de uma prática, de uma reflexão, de tomada de decisão cotidiana, da investigação empírica que se desenvolvem assentadas em valores e princípios na maioria das vezes não explicitados.

Assim, ganham realce as questões relativas à profissionalização do professor, encarada como uma das estratégias para repensar a dinâmica da formação em saúde em suas dimensões institucional e social: pensar a docência como profissão influencia toda e qualquer iniciativa de ampliação de vínculo institucional dos professores e de aumento de tempo de dedicação à escola.

Batista e Batista ${ }^{8}$ acreditam que é necessário resgatar o processo ensino-aprendizagem como intencional, mobilizador de saberes e que se coloque como uma prática construída nas interações com os alunos, seus pares e com o conhecimento. Nessa perspectiva, ensinar não abrange a repetição desvinculada do contexto e nem uma cristalização dos produtos científicos, antes pode significar a construção de olhares críticos forjados a partir de apropriações dos conhecimentos já produzidos, instaurando espaços de incorporação, criação e socialização de novos conteúdos, formas de trabalho e relações sociais.

Hurst $^{7}$ situa o professor como um sujeito que se compromete com o aluno, buscando não somente mediar o acesso aos conteúdos e informações, mas apreender como o aluno utiliza as ferramentas elaboradas na universidade, o que tem significado para o exercício de sua condição de cidadão, como pensa e age em situações complexas da vida profissional.

Esta perspectiva encontra ressonância nos processos de implementação das Diretrizes Curriculares Nacionais (DCN) do Curso de Medicina, as quais indicam a necessidade de mudar o foco da retenção/acúmulo de informações para os movimentos de contextualização, integração, compreensão, aplicação e produção de conhecimentos ${ }^{3}$. Recoloca-se, desta forma, a posição do estudante: de um lugar passivo, como receptáculo, para uma postura ativa, de construtor de conhecimento.

Articular o ensino e a aprendizagem, entendendo-os como processos dialeticamente imbricados, é um desafio contemporâneo. Neste contexto, parte-se de uma concepção de docência que imbrica os processos de produção, construção e apropriação de conhecimentos numa perspectiva histórico-social, considerando os condicionantes culturais e políticos do processo do adoecer implicados na assistência, compreendida como prática social que revela as complexas relações presentes no cuidado à saúde.

Conhecer o professor de Medicina, suas experiências, saberes e práticas significa investir em movimentos de comparação, 
explicação, interpretação e teorização, num momento em que o ensino médico busca caminhos éticos, humanistas, competentes e socialmente comprometidos.

\section{METOLOGIA}

\section{Sujeitos e procedimentos}

Constituíram a população de estudo investigada 21 professores em atividade e aposentados, sendo 4 docentes por década investigada (1960, 1970, 1980, 1990), exceto a década de 1950, em que foram entrevistados 5 docentes.

O tamanho desta amostra se delineou a partir das características do procedimento de coleta de dados escolhido (entrevista semiestruturada), bem como das possibilidades de acesso ao conjunto de professores. Um terceiro aspecto bastante decisivo na delimitação dos professores investigados é o princípio de saturação nas respostas, apontado por Minayo e que se destaca nos estudos de significados e/ou concepções: a coleta se encerra quando os dados evidenciam um grau de repetição nos argumentos, percepções, sentidos.

Os critérios de inclusão dos sujeitos, construídos a partir da literatura, envolveram, além da década de ingresso, o nível de titulação (graduação, especialização, mestrado e doutorado) e a inserção em departamentos acadêmicos (Clínica Cirúrgica, Clínica Médica, Tocoginecologia). Foi solicitada uma lista de docentes ao Setor de Recursos Humanos da Universidade Federal de Alagoas (Ufal) a partir desses critérios, empreendendo-se um sorteio dos professores.

Para a década de 1950, considerando as características e condições físicas e mentais dos docentes, optou-se por contatar os professores e, dependendo da situação em que estivessem e de seu interesse, a entrevista seria realizada. Assim, foram entrevistados cinco professores, que, quando procurados, manifestaram interesse em conceder a entrevista.

Na década de 1960, o sorteio considerou somente o critério "inserção em departamento acadêmico", pois os professores apresentavam somente a graduação porque na época os cursos de pós-graduação praticamente inexistiam no Nordeste, e os deslocamentos do Estado eram raros.

Nas décadas de 1970, 1980 e 1990, o sorteio cruzou os dois critérios, sendo que a graduação como único título somente foi encontrada nos anos 1970 (apenas um professor nesta condição).

Com a amostra constituída, foram feitos os contatos para realizar as entrevistas, orientadas por um roteiro composto por dois núcleos orientadores: trajetória do professor de Medicina (inser- ção, experiências docentes, processo de formação) e concepções docentes: o ensinar e o aprender em Medicina.

As entrevistas foram gravadas e transcritas pela pesquisadora e foi utilizado um diário de campo, que registrou aspectos relativos ao clima da entrevista, comportamento dos professores durante as entrevistas e percepções da entrevistadora.

A análise de dados foi realizada no escopo da análise de conteúdo, focalizando o tipo da temática. Os resultados foram organizados em torno de quatro núcleos de significado: perfil dos professores, inserção na docência médica, concepções de ensino-aprendizagem e trajetórias docentes.

O projeto foi aprovado pelo Comitê de Ética da Universidade Federal de São Paulo (Protocolo n⿳0 1057/04), tendo os sujeitos assinado o Termo de Consentimento Livre e Esclarecido, garantindo-se o sigilo dos dados coletados, bem como o direito às informações necessárias.

\section{RESULTADOS E DISCUSSÃO}

\section{Professores de Medicina da UFAL: configurando um perfil}

Os professores da década de 1950, todos do sexo masculino, apresentam faixa etária média de 80 anos, com uma atuação docente ininterrupta de cerca de 40 anos. São graduados no curso de Medicina, a maioria com estágios nas respectivas especialidades. Exerciam a medicina em seus consultórios particulares e hospitais públicos, o que, talvez, possa implicar que suas atividades primordiais não eram relacionadas ao exercício docente. Um dado interessante é que um deles afirmou ter feito, nos anos 1940, um curso de didática de ensino.

Os professores da década de 1960 têm, em média, 70 anos de idade, apresentando um período de cerca de 30 anos como docentes do curso médico. Duas características são marcantes entre eles: a inserção de uma professora do sexo feminino e o fato de todos serem egressos da primeira turma de graduados na Faculdade de Medicina de Alagoas.

Os professores da década de 1970 apresentam faixa etária entre 50 e 60 anos, com um trabalho docente de 25 anos, em média. Um deles é apenas graduado, e os demais são especialistas. Nessa década, o número de professoras passa a ser equivalente ao de professores, além das características relativas à titulação: uma professora com mestrado e um professor com doutorado.

Os professores entrevistados da década de 1980, com faixa etária entre 40 e 50 anos, estão na docência médica há cerca de 17 anos. No âmbito da titulação, todos têm residência médica, além de um docente com doutorado, uma professora com mestrado e 
uma com especialização em educação médica. Nessa década, ocorre o inverso dos anos 1960, com uma significativa inserção de professoras (para cada docente do sexo masculino há três docentes do sexo feminino).

Os professores da década de 1990 têm uma média de 40 anos de idade e estão no exercício docente há aproximadamente 12 anos. Todos os professores entrevistados eram do sexo masculino. Um deles tem pós-doutorado, e os demais são especialistas. O perfil dos professores está apresentado no Quadro 1.

Quadro 1

Características do perfil docente por década de ingresso, sexo, idade, anos de atuação docente e formação

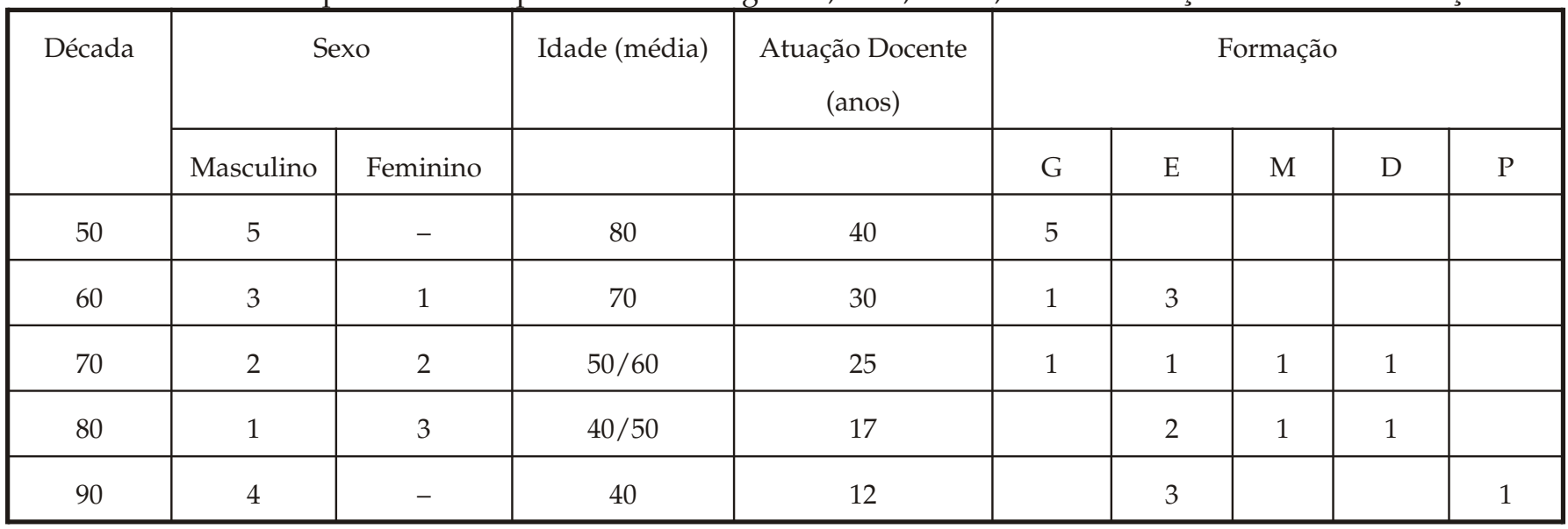

$\mathrm{G}=$ graduação; $\mathrm{E}=$ especialista; $\mathrm{M}=$ mestrado; $\mathrm{D}=$ doutorado; $\mathrm{P}$ = pós-doutorado.

Dentre as singularidades e especificidades que marcam os professores das diferentes décadas, considerando os contextos institucionais, políticos e educacionais locais, regionais e nacionais, verifica-se um ponto comum: em todas as décadas os professores têm como atividade principal a atuação em seus consultórios particulares, o que pode indicar um lugar secundário para a docência como atividade.

Estes dados corroboram os achados de Pimenta e Anastasiou $^{2}$ e Batista e Batista ${ }^{8}$, que, ao identificarem a secundarização da docência universitária nas trajetórias de professores médicos, destacam o quanto este fato compromete o processo de investimento na formação e desenvolvimento docente, ou seja, no processo de profissionalização docente.

\section{A inserção na docência universitária: múltiplos caminhos}

Pode-se depreender que diversos, múltiplos e singulares foram os processos de inserção docente. Identificou-se que da década de 1950 à de 1990, salvo a década de 1970, as experiências docentes anteriores à vida universitária tiveram significativa influência:
A minha inserção deu-se por formação na Escola Normal, no Sacramento e no Instituto de Educação. (P50)

Eu já ensinava quando estudante. Comecei a ensinar higiene e puericultura. Isso me motivou para a carreira docente, pois eu já tinha uma experiência razoável nesse campo pedagógico. (P80)

Desvelou-se nos depoimentos dos docentes uma compreensão que parece atribuir à experiência em si uma força bastante significativa no processo de aprendizagem da docência. Gordan ${ }^{10}$ alerta para a necessidade de produzir reflexões e críticas sobre as vivências, na medida em que complexidades do ensino-aprendizagem em medicina exigem um aprofundamento sobre as motivações docentes e suas perspectivas de educação e prática médica.

Os professores revelaram, também, que as necessidades de atender às demandas do curso de Medicina foram, também, determinantes para o ingresso na Universidade Federal de Alagoas:

Os professores fundadores entravam como titulares. Com a federalização da Faculdade pelo Governo Federal, nós passamos de titulares a catedráticos, mesmo sem termos feito concurso. (década de 1960) 
Eu nunca pensei em ser professora. Eu sou uma pessoa meio retraída [...] houve um conflito entre dois professores, alguém me pediu para dar uma aula e eu fui, terminei ficando e gostando. (década de 1980)

É necessário reconhecer que a priorização dos aspectos administrativos também pode ser compreendida a partir da consideração de que, nos primórdios da história da Faculdade de Medicina de Alagoas, havia uma carência de profissionais para compor o quadro acadêmico necessário ao funcionamento do curso. Isso talvez se explique pelo fato de as Faculdades de Medicina mais próximas estarem localizadas em Pernambuco e na Bahia, tornando o curso possível apenas para uma minoria economicamente privilegiada ${ }^{11}$.

Alguns professores atribuem sua inserção docente aos estímulos gerados por atividades que exerciam como alunos (seja em diretórios acadêmicos, seja na monitoria ou, ainda, na residência médica como recém-formados). “Durante o meu período de estudante fui presidente do diretório de medicina, tinha certa atividade e o pessoal começou a gostar mesmo das minhas aulas". (década de 1990)

Essas falas expressam uma dimensão que tem sido explorada por estudiosos da docência universitária ${ }^{2,12}$, indicando que as vivências como alunos e os modelos de professores que vão sendo incorporados motivam para a carreira docente, que é experimentada a partir de determinados modelos de ser professor no ensino superior.

Na expressão de um dos entrevistados, emergiu também o ingresso como uma questão natural, porque fazia parte de uma família cuja profissão preponderante era o magistério: Ingressei com 32 anos de idade, eu venho de uma família de docentes. Não tinha interesse em ensinar, eu não tive nem tempo de pensar. (década de 1980)

A questão da inserção docente remete aos processos identitários, expondo os motivos e as condições em que o tornar-se docente foi sendo conformado, e, em certa medida, explicando as referências que estão inscritas na maneira de ensinar. Zabalza ${ }^{12}$ argumenta:

A carreira profissional faz parte da construção da identidade profissional dos docentes desde o momento em que eles iniciam tal processo como monitores ou assistentes até alcançarem a maturidade profissional. Trata-se de um longo itinerário em que vão se mesclando muitos componentes dos mais diversos tipos: das circunstâncias pessoais e familiares até as oportunidades acadêmicas; das normas institucionais aos critérios políticos e econômicos de cada momento; das condições sociais características do momento à forma como nos afeta o próprio jogo de influências e divisão de poder que ocorra em nosso meio.

Colocar em debate a inserção docente pode ser uma produtiva fonte de subsídios para entender os estilos docentes e as opções que os professores fazem no decorrer de suas vidas acadêmicas.

\section{Concepções do processo ensino-aprendizagem}

A análise interpretativa, a partir dos dados, possibilitou compreender as concepções sobre o processo ensino-aprendizagem em três núcleos temáticos. O primeiro alude ao ensinar e aprender como fruto da interação professor/aluno, com a valorização da empatia, do respeito, da horizontalidade de relações pedagógicas:

Eu me coloco no mesmo plano, uma pedagogia horizontal e aberta, dialética; através desta dialética nós vamos chegar ao conhecimento do conceito que nós estamos dispondo ao aluno. (P50)

Não há mais nenhum motivo para o aluno depender da cultura do professor. Ele é apenas um orientador, nas suas inquietações, dos seus interesses; o professor não é mais aquele teórico que determinava e impunha a sua cultura. (P90)

Dentre as várias questões pertinentes ao processo de ensino-aprendizagem, a relação professor-aluno se impõe como elemento fundamental, por se tratar do encontro de dois sujeitos.

Numa perspectiva de integralidade, o sujeito pensa, sente, experimenta, expressando que a emoção e a afetividade fazem parte da aprendizagem. Como sujeitos diferentes, professor e alunos podem estabelecer um contato empático? Sonzogno ${ }^{13} \mathrm{CO}-$ labora na resposta a essa questão ao alertar os docentes para que ampliem suas possibilidades no processo de ensino-aprendizagem assumindo uma atitude de escuta e de observação a fim de tornar possível uma interação com o outro. A autora sugere que o docente não olhe o outro a partir de referências próprias, mas que incorpore as histórias, crenças, saberes e experiências dos alunos.

Almeida ${ }^{14}$ e Placco e Silva ${ }^{15}$ aprofundam a dimensão relacional, destacando que ser afetado pelo outro significa mobilização dos desejos e necessidades de aprender, ensinar, formar.

Imbricado a essa dimensão relacional, emerge o segundo núcleo temático - ensinar e aprender como dinâmicas de troca e transmissão de informações:

Aprendizado, hoje, é essa relação de participação do aluno e do professor em todos os níveis, desde a parte do ensino propriamente dito, da pesquisa e da extensão. (P80) 
Nesses momentos de transmissão de conhecimento com os alunos, você tenta de alguma forma empolgar, mostrar ao aluno uma correlação entre a pequena área oftalmológica no sistema como um todo, seja uma interação com a Neurologia, seja com a Endocrinologia. (P70)

O processo ensino-aprendizagem inscreve-se numa rede relacional em que o docente é reconhecido como um sujeito que ocupa um lugar de transmissão diferenciado, por destacar a necessidade da motivação. Essa concepção parece traduzir uma cultura de aprendizagem e ensino que valoriza o acúmulo de informações e a assimilação de conteúdos, fazendo uma referência tênue à prática.

O terceiro núcleo emerge como um contraponto - ensinar e aprender como produzidos numa relação docente/discente fundada na construção do conhecimento, exigindo articulação teórico-prática:

A maior experiência que eu passei como professor foi adaptar as técnicas de dinâmica de grupo para o ensino médico de Histologia e Embriologia. Aí se exigia não mais que o professor desse aula magistral, aquela aula conceitual sobre o assunto. (P60)

Aprendizado, hoje, é essa relação, construção da participação do aluno e do professor em todos os níveis, desde a parte do ensino propriamente dito, da pesquisa e da extensão. (P80)

O processo de ensino-aprendizagem, nas falas desses docentes, é complexo, não podendo ser reduzido a transmitir e adquirir informações. Batista ${ }^{16}$ destaca que o ato de ensinar não está dissociado do ato de aprender, pelo contrário, se encontra em estreita correlação. Ao pensar estratégias de ensino, ao elaborar planejamentos, o professor se indaga sobre as possibilidades cognitivas do aluno, vai além do elenco de conteúdos a serem trabalhados e se faz a pergunta: como meu aluno aprende? Com essa preocupação explicitada e na busca de respostas, amplia-se a possibilidade de estabelecer um trabalho significativo tanto para o professor como para o aluno.

A construção de uma nova cultura, fundada no conhecimento como processo de interpretação da realidade, de atribuição de significado e apropriação crítica das teorias já consolidadas, demanda, segundo Pozzo ${ }^{17}$, uma (des)construção de valores e pressupostos de professores e estudantes, estruturando ênfases na mediação, no diálogo, no estudo com significado, na produção de conhecimento.

Nesse sentido, os estudos de Chacón e Vergara ${ }^{18}$ e Oliva e $\mathrm{Cao}^{19}$ enfatizam a existência de intensos movimentos de ressig- nificação dos lugares do professor e do aluno no processo de formação e aprendizagem, em que a identidade de sujeito é atribuída não somente ao docente, mas também ao estudante.

No âmbito das concepções, identifica-se que a década de ingresso na docência médica não é um determinante explicativo isolado, mas se relaciona com outros condicionantes. Isto exige novos estudos, que possam aprofundar as dimensões histórico-culturais que conformam maneiras de pensar e fazer no ensino médico.

\section{Trajetórias de formação}

Na década de 1950, no âmbito da trajetória de formação, constata-se a importância do exemplo dos professores, da oportunidade dada ao aluno, da prática e do autodidatismo:

[...] estudei pedagogia e a minha formação na Bahia com as várias escolas cirúrgicas existentes. A grande vaidade dos professores, naquele tempo, era dar teses e as docências livres para os alunos... Fernando Luz, um dos maiores cirurgiões da época, acreditou em $\mathrm{mim}$, eu era interno dele. Ele me proporcionou leituras científicas internacionais, da França, Itália, Espanha e Argentina. Comecei a ensinar pedagogia, didática e metodologia geral. Depois, medicina clínica, cirúrgica e ginecológica.

A análise das falas dos professores das décadas de 1960 e 1970 evidencia a importância das especializações e do exemplo dos professores. Como relatou um professor:

minha formação para ser professor de medicina foi se constituindo ao observar outros professores, notadamente aquele professor de quem eu estava mais próximo, que era o professor Hélvio Auto; ele foi o grande exemplo da minha vida, não só um exemplo didático, mas, sobretudo, exemplo de vida. Fiz um curso rápido de didática do ensino superior.

Os professores das décadas de 1980 e 1990 evidenciaram a importância da residência médica, do mestrado, da formação didática. Porém, ainda é marcante a referência à postura autodidata, marca da formação que parece permear todas as décadas, sugerindo que a questão da docência como uma profissão secundarizada influencia o reconhecimento da necessidade de uma formação que supere as experiências individuais ${ }^{8}$.

Um traço que também emerge dos dados coletados é a dimensão pessoal que marca as trajetórias de formação. A pesquisa de Pimentel ${ }^{4}$ já expunha essa dimensão, mostrando o quanto as docências estão marcadas pelos processos de internalização das experiências, constituindo identidades como professores do ensino superior. 


\section{CONCLUSÕES}

Um primeiro achado apreendido faz emergir a compreensão do ensinar e do aprender em medicina: os professores entrevistados destacaram a dimensão relacional entre professor e aluno.

Nas diferentes décadas, os docentes acreditam que manter um relacionamento interpessoal caracterizado pelo diálogo, pelo respeito e pelo compromisso é condição fundamental na formação médica. Chamou a atenção, entretanto, que várias foram as referências ao ensino em seu aspecto de transmissão de informações, tendo os movimentos de aprendizagem como construção ficado em segundo plano.

O crescimento do debate contemporâneo sobre as relações professor-aluno, médico-paciente, médico-comunidade, médico-equipe de saúde, no qual os temas de humanismo e ética recebem singular realce, confere relevância a esse aspecto apreendido e sinaliza que novos estudos poderão aprofundar e qualificar o que tem sido concebido como relacionamento saudável no curso de Medicina.

Imbricado com a dimensão da relação professor-aluno, emergiu, como um segundo achado, a situação de transição de valores, pressupostos e saberes sobre o trabalho do professor de Medicina como um mediador crítico. E as falas dos professores revelam que essa transição traduz processos muito diferenciados de inserção na profissão docente (convite, necessidade administrativa e pedagógica, experiência anterior no ensino médio, tradição familiar).

Um terceiro achado abrangeu as trajetórias de formação, fortemente influenciadas pelo autodidatismo, com uma crença no esforço do próprio professor, na elaboração de saberes e na experiência como fundamentos que bastarão para sustentar a docência em Medicina. Por outro lado, os professores apontam a inexistência ou a falta de sistematização de uma formação didático-pedagógica como uma lacuna em seus itinerários na docência médica.

Este estudo aponta a necessidade de outras pesquisas que investiguem o processo ensino-aprendizagem em outros contextos institucionais e que busquem relações com os movimentos de transformação do ensino médico brasileiro e as concepções e práticas docentes.

\section{REFERÊNCIAS}

1. Abramowicz M. Avaliação, afetividade e a condição existencial do aluno. In: D'Antola A. (org.). A prática docente na universidade. São Paulo: EPU; 1992.

2. Pimenta SG, Anastasiou LGC. Docência no ensino superior. São Paulo: Cortez; 2002.

3. Rodrigues A, Esteves M. A análise de necessidades na formação de professores. Portugal: Porto; 1993.
4. Pimentel MG. O professor em construção. São Paulo: Papirus; 2003.

5. Perdigão ALRV. Concepções pessoais de futuros professores sobre os processos de aprendizagem e de ensino. In: Reali AAMM, Mizukami MGN (org.). Formação de professores: práticas pedagógicas e escola. São Paulo: EDUFSCar; 2002.

6. Mizuakami MGM. Formação de professores: práticas pedagógicas e escola. São Paulo: EDUFSCar; 2002.

7. Hurst JW. Professores e verdadeiros professores. In: Lane JC, Andreollo NA, Mantovani M (org.). O processo de ensino e aprendizagem em Medicina. São Paulo: Fundo Editorial BYK; 2004.

8. Batista NA, Batista SH (org.). Docência em saúde: temas e experiências. São Paulo: Senac; 2004.

9. Ribeiro EC. O ensino/aprendizagem na escola médica. In: Marcondes E, Lima GE. Educação Médica. São Paulo: Sarvier; 1998.

10. Gordan PA. Currículos inovadores: o desafio da inserção docente. In: Batista NA, Batista S H (org.) Docência em saúde: temas e experiências. São Paulo: Senac; 2004.

11. Verçosa EG. História do Ensino Superior em Alagoas: verso e reverso. Maceió: Edufal; 1997.

12. Zabalza M. O ensino universitário: seu cenário e seus protagonistas. Porto Alegre: ArtMed; 2004.

13. Sonzogno M.C. Metodologia no ensino superior: algumas reflexões. In: Batista NA; Batista SH. (orgs.). Docência em saúde: temas e experiências. Currículos inovadores: o desafio da inserção docente. São Paulo: Senac; 2004.

14. Almeida M. Educação Médica e Saúde: possibilidades da mudança. Rio de Janeiro;Londrina: Associação Brasileira de Educação Médica; Eduel; 1999.

15. Placco VN, Silva SH. Formação do professor: desafios e possibilidades. In: Almeida L, Placco VN. O coordenador pedagógico e a formação docente. São Paulo: Loyola; 2005.

16. Batista NA. Desenvolvimento docente na área da saúde: uma análise. Trab Educ Saúde. 2005;2(3):283-294.

17. Pozzo JI. Aprendizes e mestres: a nova cultura da aprendizagem. Porto Alegre: ArtMed, 2002.

18. Chacón EP, Vergara DL. Didáctica para el desarrollo del pensamiento crítico em estudiantes universitários. Colômbia: Universidade de Cartagena; 2002.

19. Oliva BF, Cao NN. La maestria pedagógica, su relación com el modelo comunicativo de la ensenãnza contemporânea. Educ Med. Super. 2003;17(1):5-13. 
Anexo: $\mathrm{O}$ roteiro da entrevista está disponível para consulta em http:/ / www.educacaomedica.org.br/anexos

\section{CONTRIBUIÇÃO DOS AUTORES}

A autora Ângela Maria Moreira Canuto Mendonça participou como investigadora do artigo, e a autora Sylvia Helena Souza da Silva Batista foi orientadora e participou de todos os momentos de elaboração deste trabalho.

\section{CONFLITO DE INTERESSES}

Declarou não haver.

\section{ENDEREÇO PARA CORRESPONDÊNCIA}

Ângela Maria Moreira Canuto Mendonça

Rua Francisco Laranjeiras, 101 - apto 201

Ponta Verde - Maceió

CEP. 57035-090 AL

E-mail: angela_canuto@uol.com.br 